\title{
Comparative Evaluation of Clinical Anaesthetic Efficacy of $15 \%$ Lidocaine Spray and $20 \%$ Benzocaine Gel during Removal of Arch Bars
}

\author{
Sudarssan Subramaniam Gouthaman¹, Janani Kandamani², Divya Sanjeevi Ramakrishnan³, Abdul Wahab P.U \\ ${ }^{1}$ Department of Oral and Maxillofacial Surgery, Saveetha Dental College, Saveetha Institute of Medical and \\ Technical Sciences, Chennai, Tamil Nadu, India. ${ }^{2}$ Department of Oral and Maxillofacial Surgery, Saveetha \\ Dental College, Saveetha Institute of Medical and Technical Sciences, Chennai, Tamil Nadu, India. \\ ${ }^{3}$ Department of Oral and Maxillofacial Surgery, Saveetha Dental College, Saveetha Institute of Medical and \\ Technical Sciences, Chennai, Tamil Nadu, India. ${ }^{4}$ Department of Oral and Maxillofacial Surgery, Saveetha \\ Dental College, Saveetha Institute of Medical and Technical Sciences, Chennai, Tamil Nadu, India.
}

\section{ABSTRACT}

\section{BACKGROUND}

Application of arch bar is considered as a gold standard for intermaxillary fixation (IMF) in the management of mandibular fractures. Both the application and removal of arch bars can inflict pain for patients who require IMF. For removal of the arch bars, local anaesthesia (local infiltration or conduction block) is often indicated. The study aimed at comparing and validating the efficacy of topical lidocaine spray and benzocaine gel in patients undergoing removal of arch bars.

\section{METHODS}

30 subjects were included in this prospective randomized controlled trial. Maxillary arch was chosen as the test site. 10 patients (Group A) were anaesthetized in the upper gingiva with $15 \%$ lidocaine spray and remaining 10 patients (Group B) were anaesthetized with $20 \%$ benzocaine gel, following which removal of arch bar was done. 10 patients were included in the control group (Group C) where $2 \%$ lignocaine infiltration was offered only on request. Visual analog scale and Wong-Baker Faces Pain Rating Scale was used to measure the pain perceived by the patient during the procedure.

\section{RESULTS}

The mean and standard deviation of the pain scores of Group A was $2.5 \pm 0.70$, Group B was $2.7 \pm 0.67$ and Control group was $5.5 \pm 0.85$. Both the test groups had a significant pain reduction when compared with the control group.

\section{CONCLUSIONS}

Topical application of both $15 \%$ lidocaine spray and $20 \%$ benzocaine gel provided equally efficient analgesia and can be useful alternatives to conventional local anaesthetic infiltration during arch bar removal.

\section{KEY WORDS}

Maxillomandibular Fixation, Local Anaesthesia, Oral Spray, Gels, Lidocaine, Benzocaine, Visual Analogue Scale

\author{
Corresponding Author: \\ Dr. Sudarssan S.G, \\ B7-222, Third Floor, \\ Kendriya vihar, Velappanchavadi, \\ Chennai - 600077, Tamil Nadu, India, \\ E-mail:dentistsudarssan@gmail.com
}

DOI: $10.14260 / j e m d s / 2020 / 608$

How to Cite This Article:

Gouthaman SS, Kandamani J, Ramakrishnan SD, et al. Comparative evaluation of clinical anaesthetic efficacy of $15 \%$ lidocaine spray and $20 \%$ benzocaine gel during removal of arch bars. J Evolution Med Dent Sci 2020;9(38):2791-2795, DOI: $10.14260 /$ jemds/2020/608

Submission 21-06-2020,

Peer Review 15-08-2020,

Acceptance 21-08-2020,

Published 21-09-2020.

Copyright (C) 2020 Sudarssan Subramaniam Gouthaman et al. This is an open access article distributed under Creative Commons Attribution License [Attribution 4.0 International (CC BY 4.0)] 


\section{BACKGROUND}

The second most common fracture of the maxillofacial skeleton is the mandibular fracture because of its location and its level of protrusion. Most of the mandibular fracture occurs due to road traffic accidents. ${ }^{1}$ The general principle for management of mandibular fracture is conservative treatment by intermaxillary fixation (IMF) or rigid fixation through open reduction. Even in patients of open reduction, most patients require IMF for stabilization and rigid fixation of the fracture. ${ }^{2}$ Both the application and removal of arch bars can inflict pain for patients who require IMF. The application of arch bars for conservative management of mandibular fracture requires relatively large doses of local anaesthetics. General anaesthesia is indicated for application of arch bar when an open reduction of the fracture is performed. However, for the removal of arch bars, local anaesthesia (local infiltration or conduction block) will often serve the purpose. While this may be true, many children and adults rebuff using multiple injections of local anaesthetics.

Lidocaine is classified under amine - amide group of local anaesthetics. It acts by inhibiting membrane depolarization and thereby causing nerve conduction blockade. ${ }^{3}$ In commercial preparations without adrenaline it has a $\mathrm{pH}$ of 5.0 to 6.0 with a general $\mathrm{pKa}$ of 7.7. With adrenaline, the $\mathrm{pH}$ lies within the range of 2.0 to 2.5. Its onset of action is instantaneous with the duration of action being intermediate. Lidocaine exhibits an average toxicity and is metabolized in the liver. The redistribution half - life is 8 to 9 minutes, and the elimination half-life is 45 to 60 minutes. The calculated adult toxic dose with lidocaine is $500 \mathrm{mg}$ (or $7 \mathrm{mg} / \mathrm{Kg}$ ) without adrenaline, and is increased when used with adrenaline. Usually Lidocaine in the concentration of $1 \%$ to $4 \%$ provides satisfactory topical anaesthesia. Significant level of vascular absorbance is achieved through topical application. ${ }^{4}$

Benzocaine is an ester group of local anaesthetic that has a pKa of 3.5 and $\mathrm{pH}$ of commercial preparations often lying within 4.5 and 6.0. It has a slow onset, short duration, and moderate toxicity. Benzocaine diverge in being a secondary amine when compared to other clinically used local anaesthetics, which are tertiary amines. This constricts the potential of the drug to pass through neural membranes. As a consequence, its clinical use is constrained to topical anaesthesia. The calculated toxic dose is around 200 to 300 mg. Methemoglobinemia in paediatric cases is associated with exorbitant use of benzocaine. 5

Topical lidocaine and benzocaine are commonly used for anaesthesia in various fields for procedures such as endoscopy and cystoscopy and is also used for intravenous injection in paediatric patients.6,7,8,9 Topical anaesthetic agents like lidocaine and benzocaine are convenient to use, has few side effects, can be easily applied to patients, and is inexpensive. In this study, we compare spray and gel forms of local anaesthetic using $15 \%$ lidocaine spray and $20 \%$ benzocaine gel during the removal of arch bars by measuring pain scale, to validate the efficacy of $15 \%$ lidocaine spray and $20 \%$ benzocaine gel in reduction of pain perception during arch bar removal in patients being treated for mandible fracture.

\section{METHODS}

This is a prospective, randomized, controlled clinical trial. For sample size calculation, a sampling error of $5 \%$ was considered, the power was set to $95 \%$ and a minimum sample size of 30 was obtained. The study included 30 participants who had Erich type arch bars fixed to the upper and lower dental arches with 26 - gauge stainless steel wires extending between first molar on either side for operative purpose or as conservative treatment of mandibular fracture. None of the arch bar was reinforced with cold cure or composite resins. Most participants had evidence of mild to moderate gingivitis but none showed any signs of severe periodontitis.

The institutional ethical committee clearance was obtained prior to initiation of the study. An informed consent was obtained from the participants before recruiting them into the study, after explaining to them the nature, requirements and complications of the study with a patient information sheet.

Randomization was done by simple lottery method. Patients were divided equally into three groups. Removal of the arch bar was planned to be performed with only topical application of $15 \%$ lidocaine spray without conventional infiltration of any local anaesthetic in group $A(n=10)$, with only topical application of $20 \%$ benzocaine gel without conventional infiltration of any local anaesthetic in group B (n =10), without any local anaesthetic in the control group ( $\mathrm{n}=$ 10). Only in case of severe pain and on request by the patient, mucosal infiltration of $2 \%$ lignocaine with adrenaline was administered for control group.

Maxillary arch was chosen as the test site. Group A patients received $15 \%$ lidocaine spray, 4 sprays per quadrant and side (buccal / lingual) in 1 minute. Group B patients received approximately $4 \mathrm{mg}$ of $20 \%$ benzocaine gel per quadrant and side, applied to the gingival mucosa with a toothbrush in 1 minute. After 3 minutes the participant's gingival mucosa was subjected to pinprick test using a 27 - gauge needle to test for analgesia (sharp sensation changed to blunt sensation) or anaesthesia (no sensation).

In both groups commencement of arch bar removal was done 5 minutes after the application of local anaesthetic. The arch bar was removed for all the patients by the same surgeon. While removing the maxillary arch bar the operator evaluated the patient's pain using the Wong-Baker Faces Pain Rating Scale. In case of moderate to severe pain during the procedure as evaluated by the operator or on patient's request, $0.9 \mathrm{ml}$ of $2 \%$ lignocaine with adrenaline through infiltration was offered. Immediately at the end of the procedure patients were made to evaluate the degree of pain experienced with VAS scale.

\section{Statistical Analysis}

The collected data was subjected to statistical analysis. Statistical analysis of the clinical variables was done using Statistical Package of Social Science (SPSS) version 23 (IBM Corporation, USA, 2012). ANOVA test was done to find their statistical significance. Level of significance was set as $\leq 0.05$. 


\section{RESULTS}

A total of 30 patients ( 26 males and 4 females) with 10 in each group were included in the study. Table 1 shows the demographic data of the study groups. The mean and standard deviation of the pain scores of $15 \%$ lidocaine spray group was $2.5 \pm 0.70,20 \%$ benzocaine gel group was $2.7 \pm 0.67$ and control group was $5.5 \pm 0.85$ [Table 2].

\begin{tabular}{|cccc|}
\hline & Group A & Group B & Control Group \\
\hline Sample Size (n) & 10 & 10 & 10 \\
Gender & Male - 9, Female - 1 & Male - 8, Female - 2 & Male - 9, Female - 1 \\
$\begin{array}{c}\text { Age in Years (Mean } \pm \\
\text { SD) }\end{array}$ & $27.7 \pm 4.52$ & $25.3 \pm 5.55$ & $29.4 \pm 4.83$ \\
$\begin{array}{c}\text { Weight in Kilograms } \\
\text { (Mean } \pm \text { SD) }\end{array}$ & $62.6 \pm 9.67$ & $70.1 \pm 13.55$ & $74 \pm 8.66$ \\
\hline \multicolumn{4}{|c|}{ Table 1. Demographic Data of the Study Groups } \\
\hline \multicolumn{4}{|c}{ SD = Standard Deviation } \\
\hline
\end{tabular}

\begin{tabular}{|ccccc|}
\hline Group & $\mathbf{n}$ & Mean & $\begin{array}{c}\text { Standard } \\
\text { Deviation }\end{array}$ & $\begin{array}{c}\text { Standard Error } \\
\text { Mean }\end{array}$ \\
Group A & 10 & 2.50 & 0.707 & 0.224 \\
Group B & 10 & 2.70 & 0.675 & 0.213 \\
Control Group & 10 & 5.50 & 0.850 & 0.269 \\
\hline \multicolumn{4}{c}{ Table 2. Pain Scores of the Study Groups } \\
(Mean and Standard Deviation)
\end{tabular}

ANOVA showed that the effects of at least two treatments were different $(\mathrm{P}=0.001)$. There was a significant difference between the two test groups and control group $(\mathrm{P}=0.001)$ and no significant difference between the two test groups $(\mathrm{P}=$ 0.567).

The $\mathrm{f}$ - ratio value is 50.30464 . The $\mathrm{p}$-value is $<.00001$. The result is significant at $\mathrm{p}<.05$.

\section{DISCUSSION}

From the results of this study, both $15 \%$ lidocaine spray and $20 \%$ benzocaine gel show no significant difference in their efficacy during arch bar removal. Both the spray and gel form of topical anaesthetics were equally efficient in reducing the pain perceived during the removal of arch bar. The anaesthetic efficacy of both $15 \%$ lidocaine spray and $20 \%$ benzocaine gel was evident from the fact that the pain scores were significantly lower $(\mathrm{P}<0.05)$ when compared with the control group.

One of the effective methods to control pain is local anaesthesia. Pain is usually associated with invasive procedures and ironically administration of local anaesthesia through an injection by itself can cause anxiety and fear to the patient. Among various methods and techniques to minimize the discomfort and pain caused by invasive procedures, anaesthetizing the mucosal surface remains to be an effective modality. This can be accomplished by application of cold, vibration, transcutaneous electronic nerve stimulation (TENS) and topical anaesthesia.10 On application of the topical anaesthetic agent the effect of anaesthesia is attained by the pharmacological action of the drug on the surface of the tissue. Topical anaesthetics act by blocking the signals from the peripheral sensory nerve fibers thereby altering the pain threshold. ${ }^{11}$ But topical anaesthetics anaesthetize the surface tissue only up to 2 - $3 \mathrm{~mm}$ depth. ${ }^{12}$ Various studies have been done to evaluate the efficacy of such drugs. Some study proves the effectiveness of topical anaesthetics while some studies have shown that they are no more effective than placebo. $13,14,15$

But the efficacy of topical anaesthesia varies because of many factors like the choice of drug, its concentration, site of application and duration of application. ${ }^{10}$

The general treatment principle for all mandible fractures is stabilization of the upper and lower borders of the mandible, 16 and it is recommended that IMF can be performed immediately after the injury and maintained for 4 to 6 weeks.17,18 Two commonly used intermaxillary fixation methods are Arch bars or bone screws. However, intermaxillary fixation using bone screws has less stability and flexibility when compared to arch bars. Obtaining complete intermaxillary fixation is not possible with bone screws, and open bite or improper reduction often leads to osteotomy or fracture revision; therefore, IMF using arch bars is considered as the gold standard. ${ }^{19}$

In spite of the fact that nowadays mandibular fractures are extensively treated by the rigid or semi - rigid internal fixation methods, making postoperative IMF unnecessary, the arch bars can be beneficial in numerous other purposes such as management of dentoalveolar fractures and associated fracture of the condyles and also for application of elastics. Hence intraoperative removal of these arch bars is rare and are instead removed few weeks later. For various reasons it is essential to identify those patients who have a very low threshold to pain during arch bar removal. Such patients could be given topical anaesthetics like $15 \%$ lidocaine or $20 \%$ benzocaine in spray or gel forms which would produce an adequate analgesia for a short duration of time in most of the patients. The application of the topical anaesthetic using a tooth brush is painless, rational, reasonable and simple in contrary to an invasive local anaesthetic infiltration. Owing to the reduced risk of toxic potential through topical absorption additional dose of topical anaesthetic either in spray or gel forms can be given to prolong the effect of analgesia rather than invasively administering the local anaesthetic drug by means of a needle, when needed.

With regards to forms of the local anaesthetic used both the spray and gel forms has its own advantages and drawbacks. Properties like better localization of the drug when compared with solutions and ointments, more desirable control over systemic drug absorption, greater bioavailability and lower dosage can be considered as some desirable benefits of topical gels. ${ }^{20}$ However, it is difficult for the gel to maintain contact with mucosa for adequate duration of time inside the oral cavity, where it gets diluted with time resulting in an incompetent anaesthesia. ${ }^{21}$ At the same time higher concentration of the local anaesthetic drug is available in the topical anaesthetic sprays which are readily absorbed across the mucous membrane. Therefore, topical anaesthetic sprays provide much more effective anaesthesia. Metered sprays with disposable nozzles are recommended for usage as unmetered sprays have a potential for systemic toxicity. ${ }^{22}$ "Nummit" spray used in this study fulfils this recommended criterion. It consists of a water-oil based emulsion of lidocaine hydrochloride that has a higher degree of penetration into the tissues and nerve cells. ${ }^{23}$ While this may be true, disadvantage of spray form is the difficulty to restrict the drug's effect to a confined area and reduced bio adhesion which consequently affects its efficacy. ${ }^{24}$ In spite of these disadvantages both 
lidocaine spray and benzocaine gel are commonly used in clinical practice. A similar study by Sharma A et al ${ }^{25}$ concluded that topical anaesthetic lignocaine in both gel and spray forms were equally efficient in reducing the pain during buccal infiltration anaesthesia, in children.

Another study done by Pere $\mathrm{P}$ et $\mathrm{al}^{26}$ concluded that $5 \%$ eutectic mixture of lignocaine and prilocaine (EMLA cream) can be used as an alternative to conventional infiltration local anaesthesia in reducing pain perceived during removal of arch bars.

A study conducted by Jeong YJ et al ${ }^{27}$ compared topical lidocaine gel with conventional $2 \%$ lidocaine infiltration anaesthesia during intermaxillary fixation procedure and concluded that topical lidocaine gel can be used as an alternative to conventional infiltration anaesthesia to reduce pain during IMF procedure. The gel and spray from of anaesthetic show to be an effective form of topical delivery. ${ }^{28,29}$

\section{CONCLUSIONS}

It can be concluded that $15 \%$ lidocaine spray and $20 \%$ benzocaine gel when topically applied over gingival mucosa provide adequate analgesia for arch bar removal and can be useful alternatives to conventional local anaesthetic infiltration during arch bar removal in patients who are uncooperative, do not respond well to local anaesthesia, or have needle phobia. As the analgesia lasts for 15 - 30 minutes, both $15 \%$ lidocaine spray and $20 \%$ benzocaine gel can only be advocated for procedures of shorter duration. Occasionally when patient experiences inadequate analgesia, minimum quantity of local anaesthetic must be immediately administered as supplemental infiltration without any hesitation.

Financial or Other Competing Interests: None.

\section{REFERENCES}

[1] Fischer K, Zhang F, Angel MF, et al. Injuries associated with mandible fractures sustained in motor vehicle collisions. Plast Reconstr Surg 2001;108(2):328-31.

[2] Bell RB, Wilson DM. Is the use of arch bars or interdental wire fixation necessary for successful outcomes in the open reduction and internal fixation of mandibular angle fractures?. J Oral Maxillofac Surg 2008;66(10):2116-22.

[3] Denson DD, Mazoit JX, Sinatra RS, et al. Physiology and pharmacology of local anaesthetics. In: Sinatra RS, Hord AH, Ginsberg B, et al, eds. Acute pain: mechanisms and management. St Louis Mosby Year Book 1992:685-700.

[4] Hamill JF, Bedford RF, Weaver DC. Lidocaine before endotracheal intubation: intravenous or laryngotracheal? Anaesthesiology 1981;55(5):578-81.

[5] Grum DF, Rice TW. Methemoglobinemia from topical benzocaine. Cleve Clin J Med 1990;57(4):357-9.

[6] Smith JL, Opekun A, Graham DY. Controlled comparison of topical anaesthetic agents in flexible upper gastrointestinal endoscopy. Gastrointestinal Endoscopy 1985;31(4):255-8.
[7] Patel AR, Jones JS, Babineau D. Lidocaine 2\% gel versus plain lubricating gel for pain reduction during flexible cystoscopy: a meta - analysis of prospective randomized controlled trials. J Urol 2008;179(3):986-90.

[8] Ibis M, Arhan M, Ibis T, et al. Lidocaine versus lidocaine plus benzydamine as a topical anaesthesia regimen for unsedated upper gastrointestinal endoscopy: a comparison study. Turk J Gastroenterol 2015;26(3):2247.

[9] Lawson RA, Smart NG, Gudgeon AC, et al. Evaluation of amethocaine gel preparation for percutaneous analgesia before venous cannulation in children. $\mathrm{Br} \mathrm{J}$ Anaesth 1995;75(3):282-5.

[10] Meechan JG. Effective topical anaesthetic agents and techniques. Dent Clin North Am 2002;46(4):759-66.

[11] Lee HS. Recent advances in topical anaesthesia. J Dent Anaesth Pain Med 2016;16(4):237-44.

[12] American Academy on Pediatric Dentistry Council on Clinical Affairs. Guideline on use of local anaesthesia for pediatric dental patients. Pediatr Dent 20082009;30:134-9.

[13] Gill CJ, Orr DL. A double-blind crossover comparison of topical anaesthetics. J Am Dent Assoc 1979;98(2):213-4.

[14] Rosivack RG, Koenigsberg SR, Maxwell KC. An analysis of the effectiveness of two topical anaesthetics. Anaesth Prog 1990;37(6):290-2.

[15] Garg A, Garg N, Kaur D, et al. Evaluation of efficacy of 2\% lidocaine gel and $20 \%$ benzocaine gel for topical anaesthesia. Endodontology 2016;28(1):38-41.

[16] Al-Moraissi EA, Ellis E. Surgical management of anterior mandibular fractures: a systematic review and metaanalysis. J Oral Maxillofac Surg 2014;72(12):2507.e1-11.

[17] de Amaratunga NA. Mouth opening after release of maxillomandibular fixation in fracture patients. J Oral Maxillofac Surg 1987;45(5):383-5.

[18] Amaratunga ND. The relation of age to the immobilization period required for healing of mandibular fractures. J Oral Maxillofac Surg 1987;45(2):111-3.

[19] Rodriguez ED. Facial fractures. In: Rodriguez ED, ed. Plastic surgery: Volume 3: craniofacial, head and neck surgery and pediatric plastic surgery. New York, NY: Elsevier Saunders 2013:75-6.

[20] Bhushan NVVS, Nayak RN. A comparison of the efficacy of topical application of lignocaine hydrochloride $5 \%$ gel and bupivacaine hydrochloride $5 \%$ gel for extraction of teeth. J Maxillofac Oral Surg 2010;9(2):119-26.

[21] Hersh EV, Houpt MI, Cooper SA, et al. Analgesic efficacy and safety of an intraoral lidocaine patch. J Am Dent Assoc 1996;127(11):1626-34.

[22] Malamed SF. Handbook of local anaesthesia. $5^{\text {th }}$ edn. St. Louis: Mosby 2004:119-21.

[23] Meechan JG. Intraoral topical anaesthesia. Periodontol 2000 2008;46(1):56-79.

[24] Tulga F, Mutlu Z. Four types of topical anaesthetic agents: evaluation of clinical effectiveness. J Clin Pediatr Dent 1999;23(3):217-20.

[25] Sharma A, Suprabha BS, Shenoy R, et al. Efficacy of lignocaine in gel and spray form during buccal infiltration anaesthesia in children: a randomized clinical trial. J Contemp Dent Pract 2014;15(6):750-4. 
[26] Pere P, Iizuka T, Rosenberg PH, et al. Topical application of $5 \%$ eutectic mixture of lignocaine and prilocaine (EMLA) before removal of arch bars. Br J Oral Maxillofac Surg 1992;30(3):153-6.

[27] Jeong YJ, Kim HJ, Kwon H, et al. The use of topical lidocaine gel during intermaxillary fixation procedure. J Craniofac Surg 2016;27(5):475-7.
[28] Kumar S. Newer delivery systems for local anaesthesia in dentistry. J Pharm Sci Res. 2015;7(5):252-5.

[29] Kee YL, Neelakantan P. Local anaesthetics in dentistrynewer methods of delivery. Int J Pharm Clin Res 2014;6(1):4-6. 